\title{
Single- and Double-Directional Channel Model for Antenna-Independent Propagation Modeling Modeling, Applications and Challenges -
}

\author{
Jun-ichi Takada \\ Graduate School of Engineering, Tokyo Institute of Technology \\ Meguro-ku, Tokyo 152-8550, JAPAN \\ Email: takada@ide.titech.ac.jp
}

\begin{abstract}
Among the propagation engineers for the mobile and wireless systems, single- and double-directional propagation measurements and modeling in the multipath environments are major concerns for the decade. The directional propagation model is the antenna-independent propagation model so as to evaluate the performance of the antennas in the specific wireless system. Therefore, the model is mainly beneficial to the antenna engineers. By using the directional propagation model, the user can reconstruct the channel response including antennas.

The antennas can be designed by the manufacturers even after the standardization of the transmission technology for the performance improvement. However, the performance of the antennas should be evaluated in the context of a specific system. Therefore, the reconstruction of the channel response, which consists of multipath propagation and antennas, is necessary.

This paper presents the applications of measurement-based directional propagation models conducted by the author's group. The presentation first reviews the concept of directional propagation model. Next, the measurement apparatus and the data processing approach are briefly described. Specific examples of applications, such as dedicated short-range communications (DSRC) in a tunnel, ultra-wideband (UWB) radio in a room, multiple-input multiple-output (MIMO) in a macrocell and in an office, will be presented. Finally, the issues, limitations and challenges of the directional channel measurement and modeling will be summarized.
\end{abstract}

\section{REFERENCES}

[1] M. Steinbauer, A.F. Molisch, and E. Bonek, "The doubledirectional radio channel," IEEE Antennas and Propagation Magazine, vol. 43, no. 4, pp. 51-63, Aug. 2001.

[2] R.S. Thoma, M. Landmann, and A. Richter, "RIMAX - A Maximum Likelihood Framework for Parameter Estimation in Multidimensional Channel Sounding," 2004 International Symposium on Antennas and Propagation (ISAP 2004), pp. 53-56, Aug. 2004.

[3] G.S. Ching, M. Ghoraishi, N. Lertsirisopon, J. Takada, I. Sameda, H. Sakamoto, and T. Imai, "Analysis of DSRC Service Over-Reach inside an Arched Tunnel," IEEE Journal on Selected Areas in Communications, vol. 25, no. 8, pp. 1517-1525, Oct. 2007.

[4] K. Haneda, J. Takada, and T. Kobayashi, "Cluster Properties Investigated from a Series of Ultra Wideband Double Directional Propagation Measurements in Home Environments," IEEE Transactions on Antennas and Propagation, vol. 54, no. 12, pp. 3778-3788, Dec. 2006.

[5] M. Landmann, K. Sivasondhivat, J. Takada, I. Ida, and R. Thoma, "Polarisation Behaviour of Discrete Multipath and Diffuse Scattering in Urban Environments at 4.5GHz,’ EURASIP Journal on Wireless Communications and Networking, vol. 2007, ID 57980, 2007.

[6] G.S. Ching, M. Ghoraishi, N. Lertsirisopon, J. Takada, I. Sameda, R. Soma, H. Sakamoto, and T. Imai, "Analysis and Modeling of DSRC Service Over-Reach inside an Arched Transportation Tunnel," 14th World Congress on ITS, Oct. 2007.

[7] K. Haneda, J. Takada, and T. Kobayashi, "Applicability of UWB Double Directional Propagation Modeling for Evaluating UWB Transmission Performance," 2007 Spring IEEE Vehicular Technology Conference (VTC 2007 Spring), Apr. 2007.

[8] K. Sivasondhivat, J. Takada, Y. Nakaya, I. Ida, and Y. Oishi, "Verification of Kronecker MIMO Channel Model in an NLOS Macrocellular Environment," 2006 IEICE General Conference, B-1-233, Mar. 2006.

[9] H. Tanaka, J. Takada, A. Honda, S. Hossain, I. Ida, and Y. Oishi, "BER Performance of Planar ESPAR Antennas in $2 \times 2$ MIMO Transmission in an Office Environment," 2007 Internationl Symposium on Antennas and Propagation (ISAP 2007), Aug. 2007.

[10] A.F. Molisch, M. Steinbauer, M. Toeltsch, E. Bonek, and R.S. Thoma, "Capacity of MIMO systems based on measured wireless channels," IEEE Journal on Selected Areas in Communications, vol. 20, no. 3, pp. 561-569, Apr. 2002.

[11] M. Landmann, M. Kaeske, R. Thoma, J. Takada, and I. Ida, "Measurement Based Parametric Channel Modelling Considering Estimated Diffuse Scattering and Specular Components," 2007 Internationl Symposium on Antennas and Propagation (ISAP 2007), Aug. 2007.

[12] P. Suvikunnas, M. Mustonen, and P. Vainikainen, "A Novel MIMO Antenna Evaluation Method for Ad-Hoc-Based Communications Systems," 2007 Spring IEEE Vehicular Technology Conference (VTC 2007 Spring), Apr. 2007.

[13] A. Richter, "The Contribution of Distributed Scattering in Radio Channels to Channel Capacity: Estimation and Modeling," Fortieth Asilomar Conference on Signals, Systems and Computers (ACSSC '06), Oct.-Nov. 2006. 